\title{
Дурягина Е.Г. \\ Роль самостоятельной работы при изучении химии студентами естественнонаучного направления
}

Российский Государственный Гидрометеорологический Университет (Россия, Санкт-Петербург)

doi: 10.18411/trnio-01-2022-65

\section{Аннотация}

В данной статье показано значение самостоятельной работы при изучении химии студентами естественнонаучного направления.

Ключевые слова: химия, самостоятельная работа, естественнонаучное направление, познавательная деятельность.

\footnotetext{
Abstract

This article is about role of self-training during study of chemistry by students of naturalscience subjects.

Keywords: chemistry, self-training, natural-science subjects, cognitive activity.
}

Важнейшей задачей, стоящей перед высшей школой, является подготовка высокообразованных людей и высококвалифицированных специалистов. Приоритетным направлением в образовании является формирование личности, способной к профессиональной самореализации в стремительно изменяющихся социальноэкономических условиях. Как заявлено в «Национальной доктрине образования в Российской Федерации» [1] основными целями и задачами образования является разностороннее и своевременное развитие молодого поколения, его творческих способностей, формирование навыков самообразования и самореализации личности, непрерывность образования в течение всей жизни человека.

Проводимая в настоящее время модернизация системы профессионального образования требует активизации и интенсификации учебного процесса — создания ряда дидактических условий, приводящих к интенсивному усвоению понятий, законов и теорий при активном участии индивидуумов. Важную роль в создании таких дидактических условий играют формы организации обучения. Посредством формы организации осуществляется «основное педагогическое воздействие на учащихся, их вовлечение в учебную деятельность, достигается педагогический результат» [2. С. 40].

С вступлением в действие новых федеральных государственных образовательных стандартов высшего профессионального образования произошло перераспределение учебной нагрузки: уменьшился объем аудиторных часов и увеличился объем часов, отводимых на самостоятельную работу, произошла замена пассивного слушания на самостоятельную работу студентов. Увеличение количества часов, отводимых на самостоятельную работу в учебных планах дисциплин в высших образовательных учреждениях, является, закономерным и позволяет совершенствовать практические умения студентов, а так же приближает академическое образование в вузах к будущей профессиональной деятельности.

Студенты высших учебных заведений должны не только получать знания по предметам программы, овладевать навыками и умениями использования этих знаний, методами исследовательской работы, быть способными к профессиональному росту и профессиональной мобильности в условиях информатизации общества и развития новых наукоемких технологий; но также уметь самостоятельно приобретать новые научные знания. Поэтому в настоящее время все большее значение приобретает самостоятельная работа студентов. Центр тяжести в обучении перемещается с преподавания на учение как самостоятельную деятельность студентов в образовании. Систематическая, управляемая 
преподавателем самостоятельная деятельность студента становится доминантой в современных условиях [3].

Под самостоятельной учебной деятельностью понимают любую активную деятельность студентов, организованную преподавателем, которая направлена на выполнение поставленной дидактической цели: поиск определенного учебного материала, его проработка, систематизация, осмысление, закрепление, формирование навыков и умений. Самостоятельная работа предполагает, что студент выполняет различного рода задания, включающие в себя программный материал, который не освещался во время аудиторных занятий. Данный вид деятельности способствует развитию и активизации творческой деятельности студентов и может рассматриваться в качестве главного резерва повышения качества подготовки специалистов [4, с. 28].

Ее можно представить как вид деятельности, при котором снижен прямой контакт с преподавателем, при этом студенты находят нужную информацию, получают новые знания, умеют оперировать ими и выполняют различные учебные задания.

К рассмотрению вопроса о роли самостоятельной работы студентов обращались многие ученые: Н.А. Введенский, Н.Г. Дайри, Р.Г. Лемберг, Г.М. Муртазин и другие [5]. Тем не менее, единого понимания самостоятельной работы не сложилось. В.И. Загвязинский рассматривает ее как «деятельность студентов по усвоению знаний и умений, которая протекает без непосредственного руководства преподавателя, хотя и направляется им» [6]. П.И. Пидкасистый, Л.М. Фридман и М.Г. Гарунов считают, что самостоятельная работа студентов является средством организации учебного или научного познания, которое выступает в качестве: 1) объекта их деятельности, задаваемого преподавателем, программированным пособием или обучающей программой; 2) формы проявления студентом определенного способа деятельности по выполнению соответствующего учебного задания, приводящего его к получению нового задания или углублению имеющегося[7]. И.А. Зимняя рассматривает самостоятельную работу как организуемую самим обучаемым в максимально удобный и рациональный, с его точки зрения, период; контролируемую им самим в процессе и по результату деятельность на основе опосредственного системного управления ею со стороны [6]. И.В. Попова интерпретирует самостоятельную работу, как особую форму обучения по заданию преподавателя, «выполнение которой требует творческого подхода и умения получать знания самостоятельно» [8]. В.П. Шишкина отмечает, что самостоятельная работа студента выступает в качестве высшей формы учебной деятельности, формой самообразования, которая осознана им как свободная по выбору и внутренне мотивированная деятельность [9]. Э.В. Губернаторов рассматривает самостоятельную работу, как важнейшую форму организации учебного процесса в вузе, которая выполняется без непосредственного участия, но под общим руководством педагога. При выполнении самостоятельной работы проявляются такие необходимые современному специалисту личностные качества, как активность, инициативность, ответственность за ход и результаты деятельности, а также формируются навыки самоорганизации и самоконтроля [3]. И.В. Попова определяет самостоятельную работу студента как особую форму обучения по заданию преподавателя, «выполнение которой требует творческого подхода и умения получать знания самостоятельно» [8], а Э.В. Губернаторова - как важнейшую форму организации учебного процесса в вузе, которая выполняется без непосредственного участия, но под общим руководством педагога. [3].

При изучении химии студентами естественнонаучного направления также происходит сокращение часов, предназначенных на аудиторное изучение дисциплины и увеличение времени, отводимого на самостоятельную работу студентов.

При изучении химии студентами естественнонаучного направления согласно рабочим программам выделяют следующие формы организации обучения: лекции, практические занятия, лабораторные занятия, самостоятельная работа. Среди видов самостоятельных работ по химии различают: практические занятия; лабораторные работы; подготовка к зачетам и экзаменам; подготовка к лабораторным работам; выполнение индивидуальных 
заданий; защита лабораторных работ, курсовых и дипломных работ; подготовка докладов и рефератов; научно-исследовательская работа.

Самостоятельная работа подразделяется на ту, которая выполняется на занятиях по химии, и на ту, которая выполняется во внеурочные часы.

Во время занятий чаще всего встречаются следующие виды самостоятельных работ: работа с лекционным материалом, изучение учебной литературы, работа со справочным материалом, решение различных задач, составление уравнений, проведение экспериментов, выполнение химических опытов, выполнение письменных самостоятельных и контрольных работ. Самостоятельная работа в аудитории, также как и внеаудиторная самостоятельная работа приучает студентов к творческому мышлению, к самоорганизации, к личной ответственности за результат. Плюсом является наличие преподавателя и других студентов, что дает возможность задать вопрос, сразу проверить ход выполнения задания, обсудить результат.

При изучении химии студентами естественнонаучного направления внеаудиторная самостоятельная работа выступает одной из основных форм ведения педагогического процесса, так как невозможно охватить весь спектр аспектов этой науки на аудиторных занятиях. При внеаудиторной самостоятельной работе приходится больше времени уделять выполнению заданий. Она предполагает индивидуальный подход к поиску необходимого материала, отбора нужной информации. При этом нет возможности сразу проверить правильность выполнения задания, задать вопрос. Поэтому внеаудиторная самостоятельная работа требует большей ответственности, большей самостоятельности. Здесь важен самоконтроль и самоорганизация, но, тем не менее, должен присутствовать контроль со стороны преподавателя.

При изучении химии студентами естественнонаучного направления существенную часть программы составляют лабораторные работы, которые позволяют получить практические навыки по овладению профессиональной деятельностью. Для эффективного их проведения, необходимо выполнение студентами самостоятельной работы при подготовке к ним, которая сводится к изучению теоретического материала, к постановке цели и задач, выполнению расчетов, написанию уравнений, а также к формулировке вопросов, которые могут возникнуть при выполнении лабораторных работ. При выполнении лабораторных работ необходимо не только фактическое их выполнение, но и составление отчетов с соответствующими расчетами и выводами, а также защита этих работ, что также предполагает самостоятельную работу.

Ключевым фактором, определяющим эффективность самостоятельной работы, является личная заинтересованность. Для развития положительного отношения студентов к внеаудиторной самостоятельной работе, необходимо разъяснение цели работы, контроль понимания этой цели, формирование у студентов умения самостоятельной постановки задачи и выбора цели.

При выполнении самостоятельной работы проявляются такие необходимые современному специалисту личностные качества, как активность, инициативность, ответственность за ход и результаты деятельности, а также формируются навыки самоорганизации и самоконтроля [9].

При всем при этом самостоятельная работа студентов естественнонаучного направления при изучении химии имеет ряд недостатков:

\footnotetext{
- отсутствие опыта в ее организации и планировании;

- плохая самоорганизация и самоконтроль;

- неумение работать со справочной и учебной литературой;

- неумение проводить сравнительный анализ, делать обобщения, выводы;

- неумение сводить теоретический материал в таблицы;

— неумение выделить главное;

- во многих случаях отсутствие мотивации, познавательной активности нежелание трудиться.
} 
Самостоятельная работа студентов является той формой обучения, которая требует от студентов активной мыслительной деятельности, умения решать различные задачи, применять ранее усвоенные знания. Ушинский К.Д. писал: «Самостоятельные мысли вытекают только из самостоятельно приобретённых знаний». Самостоятельная работа студентов формирует умение самостоятельно находить нужную информацию, необходимые издания, пользоваться справочными данными, развивает способность к исследованию, приучает к трудолюбию, к настойчивости при достижении цели. При этом развивается логическое мышление, способность творчески подходить к выполнению заданий, способность критически оценивать проделанную работу. Актуальность проблемы овладения студентами методами самостоятельной познавательной деятельности обусловлена тем, что в период обучения в вузе закладываются основы профессионализма, формируются умения самостоятельной профессиональной деятельности [10]. Поэтому особенно важным является, чтобы студенты, овладевая знаниями и способами поиска информации, осознавали, что самостоятельная работа должна завершать задачи всех других видов учебной работы, так как никакие знания, не являющиеся объектом собственной деятельности, не могут считаться подлинным достоянием личности

Учёные-классики отмечают значимость самостоятельной работы: «Самостоятельность головы учащегося - единственное прочное основание всякого плодотворного учения», считал К.Д. Ушинский, указывая, что самостоятельная работа является деятельностью по усвоению знаний и умений [11]. А. Дистервег обращал внимание, что «развитие и образование ни одному человеку не могут быть даны или сообщены. Всякий, кто желает к ним приобщиться, должен достигнуть этого собственной деятельностью, собственными силами, собственным напряжением. Извне он может получить только возбуждение...» [12].

В условиях модернизации высшей школы без целенаправленной самостоятельной работы студентов невозможно формирование современного специалиста. Образовательный процесс в вузе должен быть направлен на подготовку специалистов, способных, самостоятельно получать нужные знания и применять их на практике. Поэтому, преследуя цель повышения качества подготовки специалистов, необходимо добиться более полного получения и усвоения знаний студентами при их самостоятельной работе. Только самостоятельная работа формирует самостоятельное мышление студентов, творческий подход к решению учебных и профессиональных задач.

$$
* * *
$$

1. Постановление Правительства Российской Федерации от 4 октября 2000 г. №751 г. Москва «О национальной доктрине образования в Российской Федерации».

2. Ибрагимов Г. И. Формы организации обучения: теория, история, практика. Казань, 1998.

3. Щербакова Е.В. Самостоятельная работа студентов как важнейшая составляющая организации учебного процесса в вузе/Е.В. Щербакова. - Текст: непосредственный/Молодой ученый. - 2010. - №8 (19). - Т.2. - С. 188-190. - URL: https://moluch.ru/archive/19/1929/ (дата обращения: 10.12.2020).

4. Челнокова Е.А., Храбан Г.С. Тьюторская деятельность педагога по индивидуализации самостоятельной работы студентов // Вестник Мининского университета. 2016. №1-1(13). С.28

5. Вавилина А.В. Компетентностный подход в образовании // Новые образовательные стандарты высшей школы: традиции и инновации: сборник научных статей Всероссийской (с межд.участием) научнопрактической конференции. Саратов, 2012. С.24-27

6. Зимняя И.А. Педагогическая психология: учебник для вузов. М., 2000. 384 с

7. Пидкасистый П.И, Фридман Л.М., Гарунов М.Г. Психолого-дидактический справочник преподавателя высшей школы. М.: Пед. общ-во России, 1999. 354 с.

8. Организация самостоятельной работы студентов в ВУЗе: методические рекомендации для преподавателей и студентов института экономики очной и заочной форм обучения /сост. д-р соц. наук, проф. И.В. Попова. Кострома: КГУ им. Н.А. Некрасова, 2009. С. 4

9. Jacob E., Rottenberg L., Patrick S., Wheeler E. Совместное (групповое) обучение: Условия и возможности для изучения Академического Английского языка // TESOL Ежеквартально. 1996. P. 253-280.

10. Загвязинский В.И. Исследовательская деятельность педагога: учебное пособие для студ. высш. пед. учеб. заведений. М., 2008. С.165-172.

11. «Вестник Мининского университета» 2017 - № 1.

12. Хамдамов У.Э., Хидирбаев Ш.Е. Место самостоятельной работы студентов в учебном процессе // Молодой ученый. 2014. №11. С. 426-427. 